\title{
A Direct Method for Distribution System Load Flow Solutions
}

\author{
B Venkata Krishna, N Padma Srinivasu
}

\begin{abstract}
Load flow or power flow studies are plays vital role in power system operation and control. These load flows are used to find voltage profile, power flow and losses etc. at each and every buses and branches. Traditional $L U$ decomposition and forward-backward methods are consuming more time to run load flows due to Jacobian matrix. The proposed solution A direct approach method for distribution load flow solutions does not required any Jacobian matrix to load flow solution, hence this solution is time efficient and robust. Using special properties of distribution networks two simple matrices are formed. One is bus injection to branch current and other branch current to bus voltage matrix, by multiplying these two matrices to obtain required load flow solution.Test results gives the clear picture about this method. This method having grate capacity touse in unbalanced multiphase distribution automation applications, mostly on very large distribution systems.

This project tested with the input data of 15 bus and 33 bus radial distribution system and also a 9 bus system data which includes Distribution Generation.
\end{abstract}

Keywords : Distribution automation system radial network, distribution system power flow, distribution generation.

\section{INTRODUCTION}

One of the main aspect in the power system is maintain entire power system secure and reliable manner. For this the power system operation and control engineers must know all the values at each and every bus and branch of network. Those values contain voltage profile which is voltage magnitude and voltage angle, real power and reactive power, current flows and power losses etc. These numbers are obtained by running load flows or power flows to that network. There are various methods to solve load flows like Gauss-Seidel, Newton-Raphson, Fast-Decoupled etc., but not all methods are advantageous at all the time, some are better in transmission systems and some are in distribution systems. Gauss-Seidel and Newton-Raphson methods are not advantageous in distribution networks those are perfect for transmission systems, because transmission systems are build with mesh type networks but distribution networks arebuilt like radial type networks. Distribution system having low $\mathrm{X} / \mathrm{R}$ ratio, so conventional load flow solutions may causes ill condition to distribution system. LU decomposition and forward-backward method is suitable for distribution system to find load flow solutions but those methods are time taking methods because of $\mathrm{Y}$ admittance matrix involved in calculation. Distributed Generators are placed nearer to the

Revised Manuscript Received on September 22, 2019

* Correspondence Author

B Venkata Krishna, Assistant Professor in the Department of Electrical and Electronics Engineering at SRKR Engineering College

N Padma Srinivasu, Research Scholar in Sagi Rama KrishnamRaju Engineering College end user on distributed network. These DG's offer more reliability and secure, and also provide continuous power supply to customer. Some diesel engines and renewable energy sources such as solar energy, wind turbines, etc. are used as DG's. Distribution system contain DG's can also be solved by this method.

The distribution system efficiency is mostly depends upon the load flow algorithm. The low flow solution is executed several times during calculating the values of power flow. So time efficient and robust characteristics are necessary for distribution system to get the efficient load flow solution.In this work a simple and efficient technique is developed.

\section{ALGORITHM DEVELOPMENT}

In this direct approach method two matrices are formed from the given line and load data as an input. From the given system input data the desired matrices i.e. bus injection to branch current matrix and branch current to bus voltage matrix are developed. These matrices are developed on the bases of distribution system characteristics. In this section the BIBC and BCBV matrix development procedure will be explained as below.

For the distribution power flows current injection based design is more actual. For $\mathrm{i}^{\text {th }}$ bus, $\mathrm{S}_{\mathrm{i}}$ is indicates the complex load andwritten as

$\mathrm{S}_{\mathrm{i}}=\left(\mathrm{P}_{\mathrm{i}}+\mathrm{jQ} \mathrm{Q}_{\mathrm{i}}\right) \quad$ where, $\mathrm{i}=1 \ldots \ldots . \mathrm{N}$

And the corresponding current injection at the $\mathrm{k}^{\text {th }}$ iteration of equation is

$\mathrm{I}_{\mathrm{i}}^{\mathrm{k}}=\mathrm{I}_{\mathrm{i}}^{\mathrm{r}}\left(\mathrm{E}_{\mathrm{i}}^{\mathrm{k}}\right)+\mathrm{j} \mathrm{I}_{\mathrm{i}}^{\mathrm{i}}\left(\mathrm{E}_{\mathrm{i}}^{\mathrm{k}}\right)=\left(\frac{\left(\mathrm{B}_{\mathrm{i}}+\mathrm{Q}_{\mathrm{i}}\right)^{2}}{\mathrm{E}_{\mathrm{i}}^{\mathrm{k}}}\right)^{*}$

From the above equation (2) $E_{i}{ }^{k}$ implies bus voltage of $i^{\text {th }}$ bus at $\mathrm{k}^{\text {th }}$ iteration, $\mathrm{I}_{\mathrm{i}}^{\mathrm{k}}$ indicates the current injection of $\mathrm{i}^{\text {th }}$ bus at the $\mathrm{k}^{\text {th }}$ iteration, andthe real part $\mathrm{I}_{\mathrm{i}}^{\mathrm{r}}$ and imaginary part $\mathrm{I}_{\mathrm{i}}^{\mathrm{i}}$ of the current injection of $\mathrm{i}^{\text {th }}$ bus at the $\mathrm{k}^{\text {th }}$ iteration are mentioned.

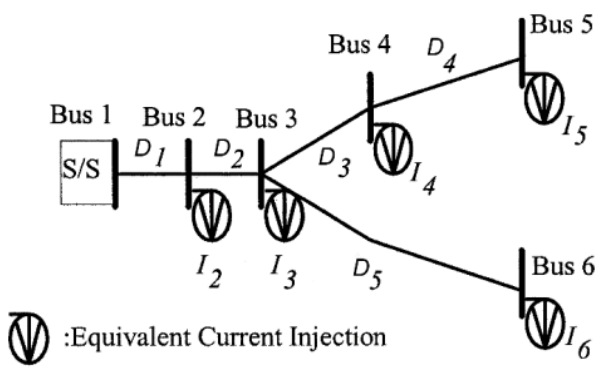

Figure 1: Simple 6 Bus Distribution System 
For an example a simple 6 bus distribution system is considered. From the equation (2), power injections can be converted to the equivalent current injections.Applying Kirchhoff's Current Law to given distribution system can be obtain the relationship among bus current injections and branch currents, and these branch currents are written in the functionof equivalent current injections, these current injections are related to the branch currents $D_{1}, D_{2}, D_{3}, D_{4}$ and $\mathrm{D}_{5}$ are shown below which is obtained from figure (A)

$$
\begin{aligned}
& \mathrm{D}_{1}=\mathrm{I}_{2}+\mathrm{I}_{3}+\mathrm{I}_{4}+\mathrm{I}_{5}+\mathrm{I}_{6} \\
& \mathrm{D}_{2}=\mathrm{I}_{3}+\mathrm{I}_{4}+\mathrm{I}_{5}+\mathrm{I}_{6} \\
& \mathrm{D}_{3}=\mathrm{I}_{4}+\mathrm{I}_{5} \\
& \mathrm{D}_{4}=\mathrm{I}_{5} \\
& \mathrm{D}_{5}=\mathrm{I}_{6}
\end{aligned}
$$

Therefore, the bus current injection and branch current are related in the above equations can be written in matrix form as

$$
\left[\begin{array}{l}
D_{1} \\
D_{2} \\
D_{3} \\
D_{4} \\
D_{5}
\end{array}\right]=\left[\begin{array}{lllll}
1 & 1 & 1 & 1 & 1 \\
0 & 1 & 1 & 1 & 1 \\
0 & 0 & 1 & 1 & 0 \\
0 & 0 & 0 & 1 & 0 \\
0 & 0 & 0 & 0 & 1
\end{array}\right]\left[\begin{array}{l}
I_{2} \\
I_{3} \\
I_{4} \\
I_{5} \\
I_{6}
\end{array}\right]
$$

The above equation (4a) represented in the simple form

$$
[\mathrm{D}]=[\mathrm{BIBC}][\mathrm{I}]
$$

Here, bus injection to branch current matrix is denoted as BIBC.

Constant BIBC matrixhaving only 0 's and +1 's, which is an upper triangular matrix as shown above.

From the Figure (A), branch currents and bus voltages are related to obtain desired equations, this shown by an example of bus 2, 3, 4 and 5voltages are

$$
\begin{aligned}
& \mathrm{E}_{2}=\mathrm{E}_{1}-\mathrm{D}_{1} \mathrm{Z}_{12} \\
& \mathrm{E}_{\mathrm{a}}=\mathrm{E}_{2}-\mathrm{D}_{2} \mathrm{Z}_{2 \mathrm{a}} \\
& \mathrm{E}_{4}=\mathrm{E}_{\mathrm{a}}-\mathrm{D}_{2} \mathrm{Z}_{24} \\
& \mathrm{E}_{5}=\mathrm{E}_{4}-\mathrm{D}_{4} \mathrm{Z}_{45}
\end{aligned}
$$

Here, $\mathrm{E}_{\mathrm{i}}$ denotes voltage of $\mathrm{i}^{\text {th }}$ bus, and $\mathrm{Z}_{\mathrm{ij}}$ represents the line impedance betweeni ${ }^{\text {th }}$ bus and ${ }^{\text {th }}$ bus.

Put equations (5a), (5b) and (5c) into (5d), we get,

$E_{5}=E_{1}-D_{1} Z_{12}-D_{2} Z_{2 a}-D_{a} Z_{a 4}-D_{4} Z_{45}(6)$

From the equation (6), we observed that the bus voltage is a functions of substation voltage, branch current and line parameters. For getting solution for other bus voltages same procedure is applied.So, the matrix is formed by relating branch currents and bus voltages as

$$
\left[\begin{array}{l}
\mathrm{E}_{1} \\
\mathrm{E}_{2} \\
\mathrm{E}_{3} \\
\mathrm{E}_{4} \\
\mathrm{E}_{5}
\end{array}\right]-\left[\begin{array}{l}
\mathrm{E}_{2} \\
\mathrm{E}_{3} \\
\mathrm{E}_{4} \\
\mathrm{E}_{5} \\
\mathrm{E}_{6}
\end{array}\right]=\left[\begin{array}{ccccc}
\mathrm{Z}_{12} & 0 & 0 & 0 & 0 \\
\mathrm{Z}_{12} & \mathrm{Z}_{2 a} & 0 & 0 & 0 \\
\mathrm{Z}_{12} & \mathrm{Z}_{2 a} & \mathrm{Z}_{34} & 0 & 0 \\
\mathrm{Z}_{12} & \mathrm{Z}_{2 a} & \mathrm{Z}_{34} & \mathrm{Z}_{45} & 0 \\
\mathrm{Z}_{12} & \mathrm{Z}_{2 a} & 0 & 0 & \mathrm{Z}_{36}
\end{array}\right]\left[\begin{array}{l}
\mathrm{D}_{1} \\
\mathrm{D}_{2} \\
\mathrm{D}_{3} \\
\mathrm{D}_{4} \\
\mathrm{D}_{5}
\end{array}\right]
$$

The above equation (7a) can be represent in simple format as, $[\Delta \mathrm{E}]=[\mathrm{BCBV}][\mathrm{D}]$

Here, branch current to bus voltage matrix denoted as BCBV.

\section{A)Formation of BIBC Matrix: \\ Step 1:}

If a distribution networkconsists $\mathrm{n}$ number of branch sections and $m$ number of buses then the size of BIBC matrix is $\mathrm{n} \times(\mathrm{m}-1)$

\section{Step 2:}

When there is ak ${ }^{\text {th }}$ branch is between $i^{\text {th }} \& j^{\text {th }}$ buses, then copy the elements of entire column related to $i^{\text {th }}$ bus on to $j^{\text {th }}$ column of D2 matrix and then set D2[k, j] =1

Step 3:

Repeat the above step number(2) till get the all branchsegments are included in the Bus Injection Branch Current matrix.

\section{B)Formation of BCBV Matrix:}

\section{Step 1:}

If a distribution networkcomprises with' $m$ ' buses and ' $n$ ' branch sections then the size of BCBV matrix will be $(\mathrm{m}-1) \times \mathrm{n}$.

\section{Step 2:}

Whenthe $\mathrm{k}^{\text {th }}$ branch is placed between $\mathrm{i}^{\text {th }}$ and $\mathrm{j}^{\text {th }}$ buses with its primitive impedance $z_{k}$ then copy the all the elements of $i^{\text {th }}$ row on to the $j^{\text {th }}$ row and then set $D 3[j, k]=z_{k}$.

Step 3:

Repeat the above Step number (2) up till all the branchunits are gathered in the BCBV matrix, substituting for B matrix results in

$$
\Delta \mathrm{E}=[B C B V][B I B C][I]=[D L F][I]
$$

Solving the above steps repeatedly, solution of load flow can be obtained. Load flow solution is obtained from DLF matrix only, which is formed by two matrices.

\section{ALGORITHM FOR DISTRIBUTION SYSTEM LOAD FLOW BY DIRECT APPROACH}

Step1: Scan the givennetwork input line and load data.

Step 2: Build BIBC matrix from given data, the equation is $[\mathrm{D}]=[\mathrm{BIBC}][\mathrm{I}]$

Step 3: From input data build BCBV matrix and the equation is

$[\triangle \mathrm{E}]=[B C B V][\mathrm{D}]$

Step 4:From obtained data form the DLF matrix.

$[\mathrm{DLF}]=[\mathrm{BCBV}][\mathrm{BIBC}]$

$$
\triangle \mathrm{E}=[B C B V][B I B C][I]
$$

$=[D L F][I]$

Step 5: Iteration count $\mathrm{k}=0$.

Step 6: Increment Iteration count $\mathrm{k}=\mathrm{k}+1$.

Step 7: Get the required voltages by the equation,

$\left[I_{\mathrm{i}}^{\mathrm{k}}\right]=\left(\frac{\left(\mathrm{P}_{\mathrm{i}}+\mathrm{Q}_{\mathrm{i}} \mathrm{j}\right.}{\mathrm{E}_{\mathrm{i}}^{\mathrm{k}}}\right)$

$\left[\Delta \mathrm{E}^{\mathrm{k}+1}\right]=[\mathrm{DLF}]\left[\mathrm{I}^{\mathrm{k}}\right]$

$\left[\mathrm{E}^{\mathrm{k}+1}\right]=\left[\mathrm{E}^{0}\right]+\left[\Delta \mathrm{E}^{\mathrm{k}+1}\right]$

Step 8: If $\max \left(\left(\left|\mathrm{E}_{i} k^{+1}\right|-\left|\mathrm{E}_{i} k\right|\right)>\right.$ tolerance $)$ go to step 6 . Tolerance taken as 0.001

Step 9: Calculate the final bus voltages.

Step 10:Stop 


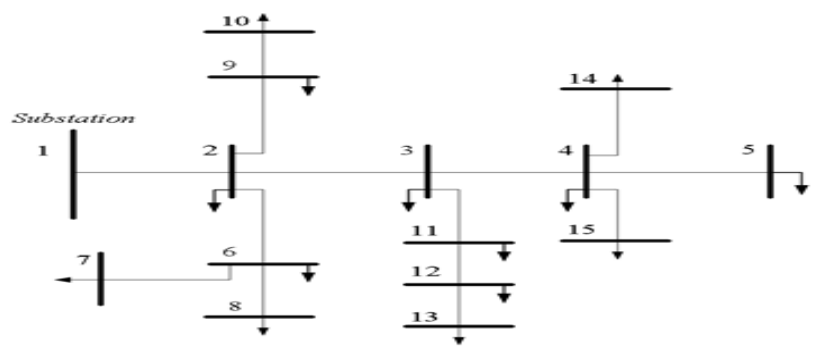

Figure 2: One Line Diagram of 15 Bus Radial Distribution System

\section{TEST RESULTS}

For 15 Bus Distribution System:

Figure (C) shows one line diagram of 15 bus, $11 \mathrm{KV}, 100$ MVA radial or tree distribution system. The voltage profile and the line flows of 15 bus system are given in Table (1) and (2). The sum of total real and reactive power loss valuesof given inputsare $61.7770 \mathrm{KW}$ and 57.2814 KVAr respectively. The lowest voltage of this system is 0.9445 p.u. occurred at bus 13 and voltage regulation is $5.55 \%$. This method takes 3 iterations and intel core CPU takes 0.034 seconds to converge.

\section{FLOW CHART FOR DISTRIBUTION SYSTEM LOAD FLOW}

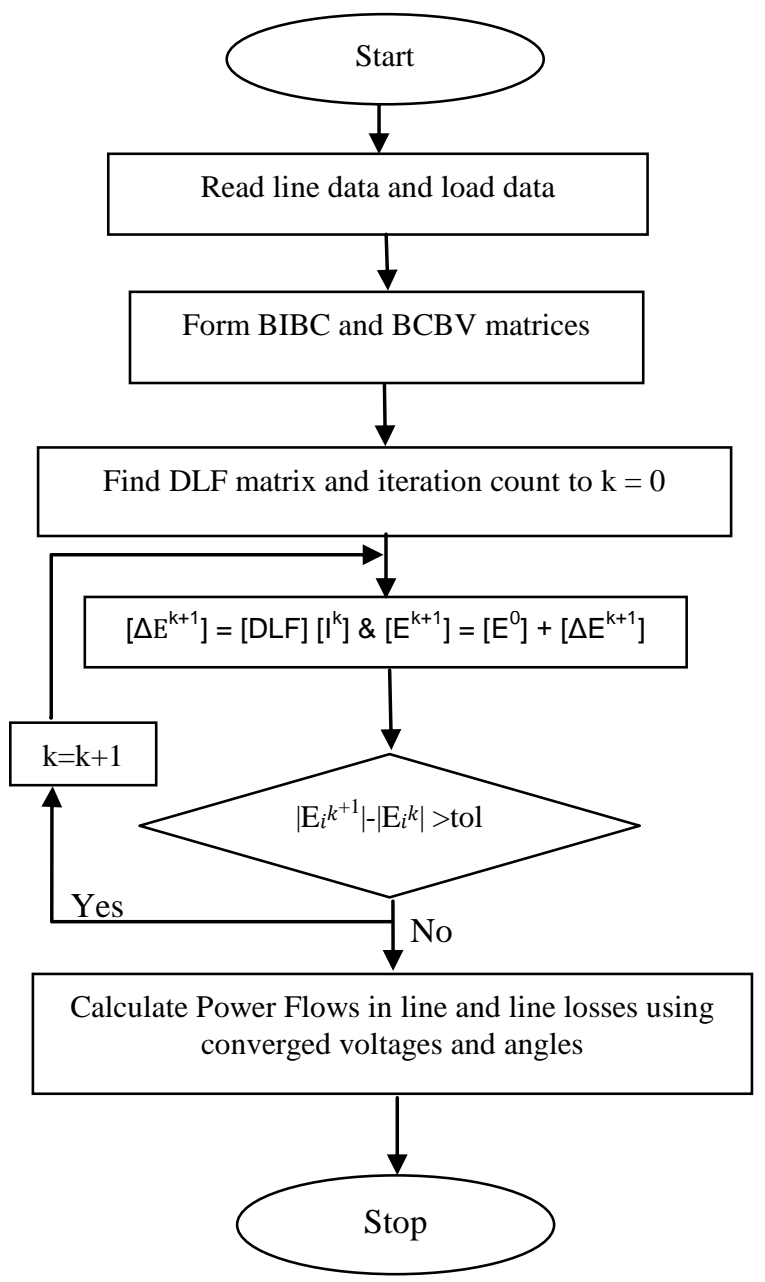

Figure 3: Flow Chart for Distribution System Load Flow
Table 1: Voltage Profile of 15 Bus Radial Distribution System

\begin{tabular}{|l|c|c|}
\hline Bus No. & $\begin{array}{c}\text { Voltage } \\
\text { Magnitude (in p.u.) }\end{array}$ & $\begin{array}{c}\text { Angle } \\
\text { (in degrees) }\end{array}$ \\
\hline 1 & 1.0000 & 0.0000 \\
\hline 2 & 0.9713 & 0.0319 \\
\hline 3 & 0.9567 & 0.0493 \\
\hline 4 & 0.9509 & 0.0565 \\
\hline 5 & 0.9499 & 0.0686 \\
\hline 6 & 0.9582 & 0.1893 \\
\hline 7 & 0.9560 & 0.2165 \\
\hline 8 & 0.9570 & 0.2050 \\
\hline 9 & 0.9680 & 0.0719 \\
\hline 10 & 0.9669 & 0.0849 \\
\hline 11 & 0.9500 & 0.1315 \\
\hline 12 & 0.9458 & 0.1823 \\
\hline 13 & 0.9445 & 0.1986 \\
\hline 14 & 0.9486 & 0.0848 \\
\hline 15 & 0.9484 & \\
\hline
\end{tabular}

Table 2: Line Flows of 15 Bus Radial Distribution System

\begin{tabular}{|c|c|c|c|c|c|c|c|c|}
\hline 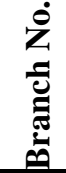 & $E=$ & $\stackrel{\theta}{\sigma}$ & $\sum_{i=1}^{\infty}$ & $\dot{3}$ & $=\approx$ & $\therefore \stackrel{3}{8}$ & $\sqrt{2}$ & 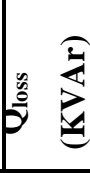 \\
\hline 1 & 1 & 2 & 1288.04 & $\begin{array}{c}1308.2 \\
4\end{array}$ & $\begin{array}{c}1250.3 \\
5\end{array}$ & $\begin{array}{c}1271 . \\
37\end{array}$ & 37.69 & 36.87 \\
\hline 2 & 2 & 3 & 735.39 & 748.45 & 724.10 & $\begin{array}{c}737.4 \\
0\end{array}$ & 11.29 & 11.04 \\
\hline 3 & 3 & 4 & 397.19 & 404.88 & 394.75 & $\begin{array}{c}402.4 \\
9\end{array}$ & 2.44 & 2.39 \\
\hline 4 & 4 & 5 & 44.15 & 45.02 & 44.09 & 44.98 & 0.06 & 0.04 \\
\hline 5 & 2 & 6 & 356.24 & 361.27 & 350.47 & $\begin{array}{c}357.3 \\
8\end{array}$ & 5.76 & 3.89 \\
\hline 6 & 6 & 7 & 140.38 & 143.08 & 139.99 & $\begin{array}{c}142.8 \\
2\end{array}$ & 0.39 & 0.27 \\
\hline 7 & 6 & 8 & 70.11 & 71.48 & 69.99 & $\begin{array}{c}71.41 \\
1\end{array}$ & 0.11 & 0.08 \\
\hline 8 & 2 & 9 & 114.62 & 116.75 & 114.15 & $\begin{array}{c}116.4 \\
4\end{array}$ & 0.47 & 0.32 \\
\hline
\end{tabular}


A Direct Approach Method for Distribution System Load Flow Solutions

\begin{tabular}{|l|l|l|c|c|c|c|c|l|}
\hline 9 & 9 & 10 & 44.16 & 45.03 & 44.10 & 44.99 & 0.06 & 0.04 \\
\hline 10 & 3 & 11 & 256.92 & 261.12 & 254.74 & $\begin{array}{c}259.6 \\
6\end{array}$ & 2.18 & 1.47 \\
\hline 11 & 11 & 12 & 114.76 & 116.84 & 114.16 & $\begin{array}{c}116.4 \\
4\end{array}$ & 0.60 & 0.41 \\
\hline 12 & 12 & 13 & 44.17 & 45.03 & 44.09 & 44.98 & 0.07 & 0.05 \\
\hline 13 & 4 & 14 & 70.19 & 71.54 & 69.99 & 71.41 & 0.20 & 0.14 \\
\hline 14 & 4 & 15 & 140.42 & 143.11 & 139.98 & 142.8 & 0.44 & 0.30 \\
\hline
\end{tabular}

\begin{tabular}{|l|l|c|}
\hline Bus No. & $\begin{array}{c}\text { Voltage } \\
\text { Magnitude (in } \\
\text { p.u.) }\end{array}$ & $\begin{array}{c}\text { Angle } \\
\text { (in degrees) }\end{array}$ \\
\hline 1 & 1.000000 & 0.000000 \\
\hline 2 & 0.999997 & -0.000067 \\
\hline 3 & 0.999994 & -0.000138 \\
\hline 4 & 0.999997 & -0.000071 \\
\hline 5 & 0.999995 & -0.000104 \\
\hline 6 & 0.999997 & -0.000060 \\
\hline 7 & 0.999995 & -0.000105 \\
\hline 8 & 0.999997 & -0.000075 \\
\hline 9 & 0.999995 & -0.000111 \\
\hline
\end{tabular}

\section{Convergence for 15 bus system:}

The plot shown is change in voltage at each iteration v/s no. of iterations for 15 bus system. For 15 bus system this method takes 3 iterations and intel core CPU takes 0.034 seconds to converge.

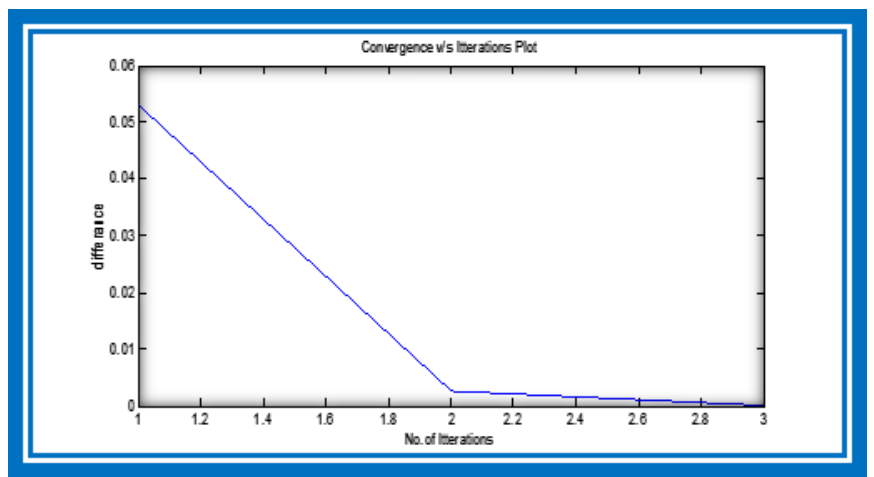

Figure 4: Convergence Characteristic on 15-Bus System

\section{Bus Distribution System with DG inputs:}

Figure (E)shows one line diagram of 9 bus, $10 \mathrm{kV}, 100 \mathrm{MVA}$ tree type distribution system. The voltage profile and the line flows of 9 bus system with distribution generation inputs are given in Tables (3) and (4).The sum of total real and reactive power loss values of given input are $0.000085 \mathrm{KW}$ and $0.000141 \mathrm{KVAr}$ respectively. The minimum voltage occurred at bus 3 i.e. 0.999994 p.u.

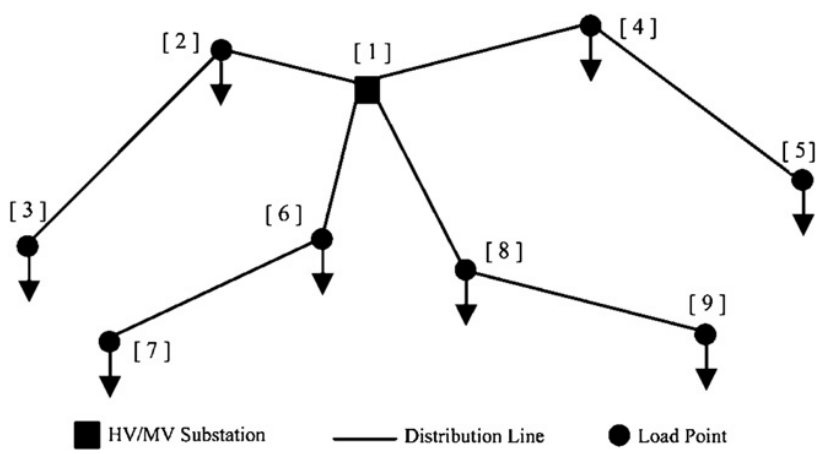

Figure 5: One Line Diagram of 9 Bus Radial Distribution System with DG input

Table (3): Voltage Profile of 15 Bus Radial Distribution System
Table (4): Line Flows of 15 Bus Radial Distribution System

\begin{tabular}{|c|c|c|c|c|c|c|c|c|}
\hline 竎 & $\stackrel{\Xi}{0}$ & $\ddot{\theta} \theta$ & 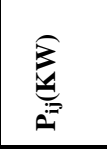 & $\approx \hat{z}$ & $=2$ & $\dot{\theta}$ & है & $\stackrel{\hat{z}}{\hat{\sigma}}$ \\
\hline \multirow{2}{*}{1} & \multirow{2}{*}{1} & \multirow{2}{*}{2} & 9.60300 & 7.20220 & 9.60298 & 7.20216 & 0.00002 & 0.00003 \\
\hline & & & 0 & 0 & 0 & 8 & 0 & 2 \\
\hline \multirow{2}{*}{2} & \multirow{2}{*}{2} & \multirow{2}{*}{3} & 5.11848 & 3.83878 & 5.11847 & 3.83876 & 0.00001 & 0.00001 \\
\hline & & & 9 & 3 & 8 & 4 & 1 & 8 \\
\hline \multirow{2}{*}{3} & \multirow{2}{*}{1} & \multirow{2}{*}{4} & 6.83240 & 5.12430 & 6.83238 & 5.12427 & 0.00001 & 0.00002 \\
\hline & & & 0 & 0 & 5 & 5 & 5 & 5 \\
\hline \multirow{2}{*}{4} & \multirow{2}{*}{4} & \multirow{2}{*}{5} & 2.34789 & 1.76089 & 2.34789 & 1.76088 & 0.00000 & 0.00000 \\
\hline & & & 5 & 2 & 2 & 8 & 2 & 4 \\
\hline \multirow{2}{*}{5} & \multirow{2}{*}{1} & \multirow{2}{*}{6} & 6.95580 & 5.21680 & 6.95578 & 5.21677 & 0.00001 & 0.00002 \\
\hline & & & 0 & 0 & 7 & 9 & 3 & 1 \\
\hline \multirow{2}{*}{6} & \multirow{2}{*}{6} & \multirow{2}{*}{7} & 4.26739 & 3.20048 & 4.26738 & 3.20047 & 0.00000 & 0.00001 \\
\hline & & & 2 & 7 & 6 & 7 & 6 & 0 \\
\hline \multirow{2}{*}{7} & \multirow{2}{*}{1} & \multirow[t]{2}{*}{8} & 6.60360 & 4.95270 & 6.60358 & 4.95267 & 0.00001 & 0.00002 \\
\hline & & & 0 & 0 & 5 & 5 & 5 & 5 \\
\hline \multirow{2}{*}{8} & \multirow{2}{*}{8} & \multirow{2}{*}{9} & 3.01709 & 2.26278 & 3.01709 & 2.26278 & 0.00000 & 0.00000 \\
\hline & & & 3 & 9 & 0 & 3 & 3 & 6 \\
\hline
\end{tabular}

\section{Convergence for 9 bus system with DG's:}

The plot shown is change in voltage at each iteration v/s no. of iterations for 9 bus system. For 9 bus system with DG's this method takes 1 iterations and intel core CPU takes 0.01919 seconds to converge. 


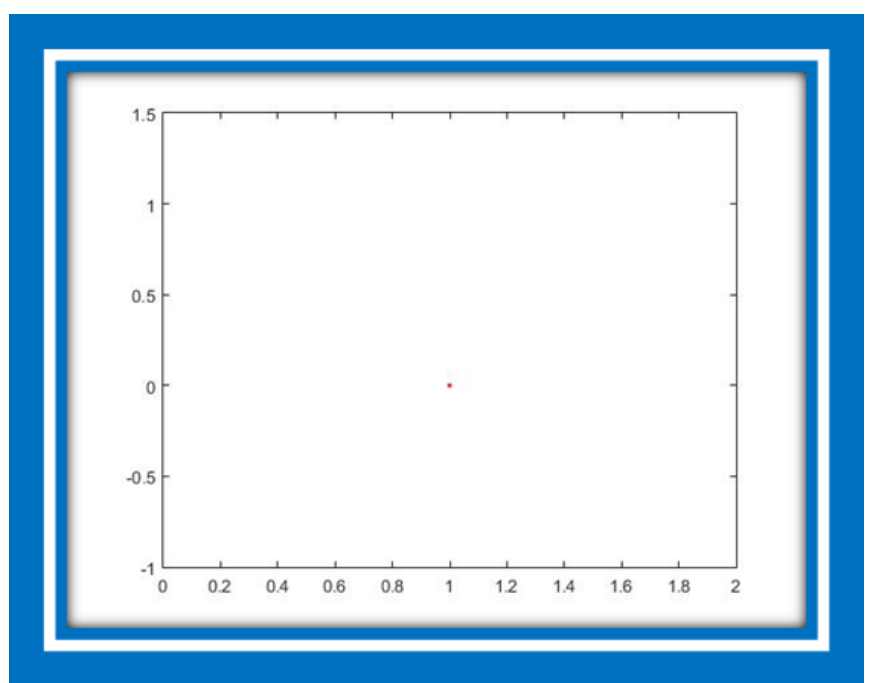

Figure 6: Convergence Characteristic on 9-Bus System with DG's

\section{CONCLUSION}

This work proposes a direct approach method for distribution load flow solutions. For this required matrices BIBC and BCBV are developed from distribution system characteristics. The BIBC implies Bus Injection Branch Current which indicate the relation between bus current injection and line current. The BCBV implies Branch Current Bus Voltage which indicate the relation between line currents and bus voltages. The distribution load flow is solved by multiplying these BIBC and BCBV matrices, which is called a direct approach method. Like LU factorization method, frequently occurred ill conditioned problem would not encountered in this method due to absence of Jacobian matrix. Due to absence of Y admittance matrix this solution is more time efficient than forward-backward substitution and LU factorization methods, which contains Jacobian matrix. And also this method converges even the distribution system contain DG's.From the case study results proposed method is efficient and robust. Finally the results from test case show that this method is mostly preferred for large-scale distribution systems.

\section{ACKNOWLEDGEMENT}

The authors acknowledge the support of Ms. Steag Energy services (I) Pvt. Ltd.

\section{REFERENCES}

1. IEEE Tutorial Course on Power Distribution Planning.

2. T.-H. Chen, M.-S. Chen, K.-J. Hwang, P. Kotas, and E. A. Chebli, "Distribution system power flow analysis - A rigid approach," IEEE Trans.Power Delivery, vol. 6, pp. 1146-1152, July 1991.

3. Babu, T. Vandana, T. Satyanarayana Murthy, and B. Sivaiah. "Detecting unusual customer consumption profiles in power distribution systems-APSPDCL." 2013 IEEE International Conference on Computational Intelligence and Computing Research. IEEE, 2013.

4. Harrison G, Piccolo A, Siano P, Wallace A. Exploring the tradeoffs between incentives for distributed generation developers and DNOs. IEEE Transactions on Power Systems 2007;22(2):821e8.

5. Rao, B. Venkateswara, et al. "Optimal power flow by Newton method for reduction of operating cost with SVC models." 2009 International Conference on Advances in Computing, Control, and Telecommunication Technologies. IEEE, 2009.
6. Arabian-Hoseynabadi $\mathrm{H}$, Oraee $\mathrm{H}$, Tavner $\mathrm{P}$. Wind turbine productivity considering electrical subassembly reliability. Renewable Energy 2010;35 (1):190e7 